\title{
High neutrophil incorporation rate of ascitic fluid cytology as an indicator of cancerous ascites
}

\author{
MISA FUJIMORI $^{1}$, HARUYO TSUCHIHASHI ${ }^{1}$, SHUMPEI FUJIMORI ${ }^{1}$, SAYAKA KOBAYASHI ${ }^{1}$, \\ YURI NOMI ${ }^{1}$, JUNKO HIRATO ${ }^{2,3}$, TETSUNARI OYAMA ${ }^{3,4}$, TOSHIO FUKUDA ${ }^{1}$ and MASANAO SAIO ${ }^{1}$ \\ ${ }^{1}$ Laboratory of Histopathology and Cytopathology, Department of Laboratory Sciences, \\ Gunma University Graduate School of Health Sciences, Maebashi, Gunma 371-8514; ${ }^{2}$ Department of Pathology, \\ Public Tomioka General Hospital, Tomioka, Gunma 370-2316; ${ }^{3}$ Department of Pathology, Gunma University Hospital; \\ ${ }^{4}$ Department of Diagnostic Pathology, Gunma University Graduate School of Medicine, Maebashi, Gunma 371-8514, Japan
}

Received October 30, 2019; Accepted August 17, 2020

DOI: $10.3892 /$ ijo.2020.5118

\begin{abstract}
The cell-in-cell phenomenon (CiCP) involves the incorporation of a viable cell by other cells (host cells) and includes two concepts: Emperipolesis and cell cannibalism. The former involves the incorporation of hematopoietic cells as the incorporated cells, while the latter involves cell incorporation by tumor cells as host cells. A total of 239 peritoneal cavity fluid cytology specimens were evaluated for $\mathrm{CiCP}$ and the number of singly detectable nuclei (SDN) were measured by examining virtual slide image files. The rates of CiCP-positive cases (RCPCs) and CiCP emergence rate (CER)/SDN were significantly higher in ascites samples than in peritoneal washing samples $(\mathrm{P}<0.0001$ and $\mathrm{P}=0.0026$, respectively), although the numbers of SDN were not significantly different between the groups $(\mathrm{P}=0.8063)$. Both the RCPCs and CER/SDN were significantly higher in tumor-positive specimens than in tumor-negative specimens $(\mathrm{P}=0.0220$ and $\mathrm{P}=0.0312$, respectively), although the numbers of SDN were not significantly different between the samples $(\mathrm{P}=0.2471)$. Most of the incorporated cells were lymphocytes and the host cells were macrophages; however, the rate of neutrophil incorporation (NI) by host cells in the total $\mathrm{CiCP}$ cells in a sample was significantly higher in tumor-positive specimens than in tumor-negative specimens $(\mathrm{P}=0.0288)$. NI was mainly performed via emperipolesis by macrophages, with only six examples not by macrophages observed among all CiCP samples. The threshold NI rate/total CiCP (NI/CiCP) between tumor-positive and tumor-negative groups was $11.1 \%(\mathrm{P}=0.0115)$. Using this threshold, the peripheral blood
\end{abstract}

Correspondence to: Professor Masanao Saio, Laboratory of Histopathology and Cytopathology, Department of Laboratory Sciences, Gunma University Graduate School of Health Sciences, 39-22, 3-chome, Showa-machi, Maebashi, Gunma 371-8514, Japan E-mail: saio@gunma-u.ac.jp

Key words: emperipolesis, cell cannibalism, cytology, whole-slide imaging, image analysis leukocyte count was significantly higher in the high-NI/CiCP group than in the low-NI/CiCP group $(\mathrm{P}=0.0022)$. The present findings revealed novel aspects of less frequently observed $\mathrm{CiCP}$ in ascitic fluid cytology by utilizing combined manual and computer assisted image analysis evaluation of samples. Notably, the present study indicated the importance of increased NI as an indicator of cancerous ascites.

\section{Introduction}

The phenomenon of 'living cell incorporation by another cell (host cell)' was initially observed in 1925 (1). Humble et al (2) subsequently named this phenomenon 'emperipolesis', a Greek term meaning 'inside round about wandering'. One of the histopathological characteristics of emperipolesis is the formation of a 'clear halo' around the engulfed living cells (3). Emperipolesis is classified into three types: Megakaryocytic, histiocytic and tumor cell emperipolesis (4). In detail, examples of emperipolesis include lymphocyte incorporation by megakaryocytes (5), lymphocyte incorporation by histiocytes in Rosai-Dolfman's disease $(6,7)$ and neutrophil incorporation (NI) by cancer cells (8). The most important criterion for emperipolesis is that the engulfed cells are hematopoietic cells, such as lymphocytes, plasma cells, erythrocytes or neutrophils $(3,4,8)$. A similar halo formation around a living cell incorporated into host cells is also observed in cell cannibalism; however, in this case the halo-like structure around the incorporated cells is termed 'bird's eye' (9). In cell cannibalism, the host cells use incorporated cells for their nutritional support or incorporate immune cells to avoid immune surveillance (9). Cell cannibalism is frequently observed in several types of tumor, including lung cancer, breast cancer and renal cell carcinoma $(10,11)$. In both emperipolesis and cell cannibalism, cell engulfment involves active penetration into the host cells (12). By contrast, phagocytosis is a process in which a cell surrounds and engulfs particles or dead cells (13). Therefore, the distinct halo formation in cell-in-cell phenomena (CiCP), including emperipolesis and cell cannibalism, distinguishes them from phagocytosis.

For cytological specimen evaluation, the focus is on detection of atypical cells, and background cell 
characteristics, such as components of inflammatory cells, are rarely considered (14), for example in special tumor cell types with lymphocyte infiltration such as Warthin tumor of the salivary glands (15) and seminoma of the testis/dysgerminoma of the ovary (16). Numerous studies describing emperipolesis and cell cannibalism are either about experiments that utilized cytological specimens or case reports $(5,8,17-20)$. However, in light of recent advancements in other techniques, including immunocytochemistry, in-situ hybridization and reverse transcription-quantitative PCR (21), cytological evaluations should consider other characteristics, focusing on less frequently observed findings such as $\mathrm{CiCP}$, in addition to routinely observed characteristics, including cellular atypia (22).

The present study aimed to analyze human cytological specimens from the peritoneal cavity for $\mathrm{CiCP}$ and to evaluate its significance in cytological evaluations.

\section{Materials and methods}

Ethics approval. The present study was approved by the Gunma University Ethical Review Board (GUERB) for Medical Research Involving Human Subjects of Gunma University School of Medicine, and the written notification for the current study was presented publicly on the webpage of Gunma University Hospital. Furthermore, the possibility to decline participation in this study was provided according to the Ethical Guidelines for Medical and Health Research Involving Human Subjects of the Japanese government (Ministry of Education, Culture, Sports, Science and Technology, and Ministry of Health, Labour and Welfare) (23). Informed consent was waived by the GUERB based on the aforementioned guidelines due to the retrospective nature of the study.

Cases and sample selection. The electronic health record system of Gunma University Hospital (Maebashi, Japan) was reviewed, and 239 successive samples of peritoneal cavity fluid between January 2011 and December 2011 were selected for cytological specimen collection of Papanicolaou staining (Pap smear), including ascites and peritoneal washing. A total of 66 cases were excluded from the present study for several reasons, including insufficient number of cells or blood contamination (Fig. 1). The clinicopathological characteristics of each case are summarized in Table I. The male to female ratio of the utilized 173 samples was 38 to 135 , and the mean age was 57.22 years (age range, 13-89 years).

Evaluation of specimens, cytological classification and grouping. Cytological classification was based on Papanicolaou's classification (Table II) (24). The specimens with negative cytology, including 'normal' and 'reactive' cytology, were defined as the 'negative group', while the specimens with suspicious/malignant cytology, including 'suspicious', 'suspicious for malignancy' and 'malignant' cytology, were defined as the 'positive group'.

Screening and determination of $\mathrm{CiCP}$. CiCP was defined as the presence of a clear peri-cellular halo of the incorporated cells inside the host cells (Fig. 2A). Smears from 173 cases, prepared according to routine hospital protocols, were examined for

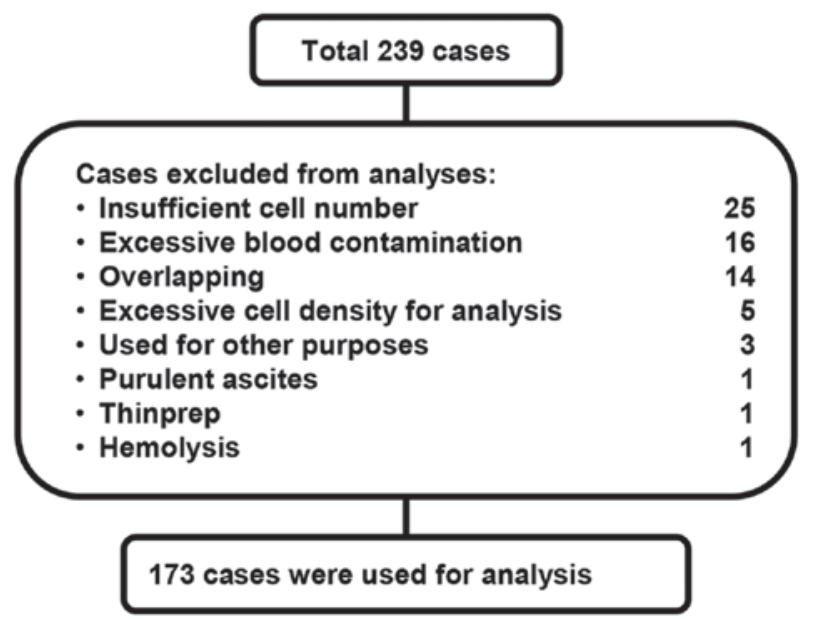

Figure 1. Selected cases and exclusion criteria. A total of 239 cases were selected from the pathology reporting system, and 66 cases were excluded from the present study. The exclusion criteria and number of cases excluded for each criterion are presented.

$\mathrm{CiCP}$ by manual screening of $\mathrm{a} \geq 1-\mathrm{cm}^{2}$ area of the smears. Two observers independently screened each $\mathrm{CiCP}$ candidate on the glass slides and marked it using a thin-tipped indelible marker. $\mathrm{CiCP}$ candidate cells were imaged under a light microscope using a x40 magnification (BX51; Olympus Corporation) and a digital camera (DP-22; Olympus Corporation), and captured with auto-white balance as a TIFF file $(1,920 \times 1,140$ pixels) using an image capture software (cellSens Standard v2.1; Olympus Corporation) and manual focusing. Dead cells or unclear samples were excluded, while samples exhibiting a clear 'peri-cellular halo of incorporated cells inside host cells' were selected as CiCP. Furthermore, a cytopathologist and a cytotechnologist characterized the types of host cells and engulfed cells on the basis of their morphological characteristics.

Evaluation of nuclear area (NA) for host cell and incorporated cell in CiCP. The NA of each host and incorporated cell was manually traced on the TIFF files and calculated using Image Pro v10 image analysis software (Nippon Roper K.K.).

Whole-slide imaging and detection of a singly detectable nucleus (SDN). Whole-slide imaging of specimens was performed using a Nanozoomer SQ Virtual Slide Scanner (VS; Hamamatsu Photonics K.K.) with a x40 magnification. The specifications of the Nanozoomer SQ were as follows: Objective lens, x20 with 0.75 numerical aperture; scan mode, x40 mode; maximum capture size, 26x76 mm; pixel size, $0.23 \mu \mathrm{m} /$ pixel; light source, light-emitting diode; image-saving format, JPEG with compression; and focus mode, autofocus. The VS image files were converted to MRXS files using Slide converter (v1.14; 3DHISTECK Ltd.) and were then analyzed using Pannoramic Viewer v1.15.4 and the Quant Center HistoQuant module (both 3DHISTECK Ltd.). For identification of a SDN using the aforementioned softwares, two general protocols were used for small and large cells $\left(10-85 \mathrm{~mm}^{2}\right.$ and $86-150 \mathrm{~mm}^{2}$, respectively) in 100 specimens due to the processing capacity of the computer used for analysis. Subsequently, the separately analyzed data were combined. 
Table I. Clinicopathological summary of the cases $(n=173)$ used in the present study.

\begin{tabular}{|c|c|c|}
\hline Organs & Histological diagnosis & Cases, $\mathrm{n}$ \\
\hline \multirow[t]{2}{*}{ Stomach $(n=43)$} & Adenocarcinoma $^{\mathrm{a}}$ & 41 \\
\hline & Gastrointestinal stromal tumor & 2 \\
\hline \multirow[t]{2}{*}{ Uterine corpus $(n=30)$} & Endometrioid carcinoma $(n=24)$, serous carcinoma $(n=2)$, mixed carcinoma $(n=1)$ & 27 \\
\hline & Carcinosarcoma $(n=2)$, endometrial stromal sarcoma $(n=1)$ & 3 \\
\hline \multirow[t]{3}{*}{ Ovary $(n=25)$} & $\begin{array}{l}\text { Serous carcinoma }(n=7) \text {, endometrioid carcinoma }{ }^{b}(n=5) \text {, clear cell carcinoma }(n=4) \text {, } \\
\text { Mucinous carcinoma }(n=2) \text {, malignant brenner tumor }(n=1) \text {, carcinoma mixed } \\
\text { subtypes }(n=1)\end{array}$ & 20 \\
\hline & Carcinosarcoma $(n=2)$, granulosa cell tumor $(n=1)$, immature teratoma $(n=1)$ & 4 \\
\hline & Malignant (histology unknown) & 1 \\
\hline \multirow[t]{3}{*}{ Cervix $(n=20)$} & Squamous cell carcinoma $(\mathrm{n}=9)$ and carcinoma in situ $(\mathrm{n}=2)$ & 11 \\
\hline & Adenocarcinoma $(\mathrm{n}=5)$ and adenocarcinoma in situ $(\mathrm{n}=2)$ & 7 \\
\hline & Adenosquamous carcinoma & 2 \\
\hline \multirow[t]{2}{*}{$\begin{array}{l}\text { Others (malignant; } \\
\mathrm{n}=18 \text { ) }\end{array}$} & $\begin{array}{l}\text { Adenocarcinoma (rectum } n=3 \text {, bile duct } n=1 \text {, pancreas } n=1 \text {, total } n=5 \text { ), serous } \\
\text { carcinoma (fallopian tube, } n=3 \text { ), squamous cell carcinoma (esophagus } n=1 \text {, vagina } n=1 \text {, } \\
\text { total } n=2 \text { ), urothelial carcinoma (bladder, } n=2 \text { ), mucinous neoplasm (appendix, } n=1 \text { ), } \\
\text { Invasive ductal carcinoma (breast, } n=1 \text { ), malignant lymphoma (lymph nodes, } n=1 \text { ) }\end{array}$ & 15 \\
\hline & Carcinoma of unknown origin & 3 \\
\hline Others (borderline, & Borderline tumors (ovary): mucinous $(n=3)$, serous $(n=2)$, endometrioid $(n=1)$ & 6 \\
\hline Precancerous; $\mathrm{n}=8$ ) & Cervical dysplasia: squamous $(n=1)$, glandular $(n=1)$ & 2 \\
\hline \multirow[t]{2}{*}{ Others (benign; $\mathrm{n}=22$ ) } & $\begin{array}{l}\text { Benign (ovary) teratoma }(n=6) \text {, epithelial tumor }(n=4) \text {, sex cord-stromal tumor }(n=2) \text {, } \\
\text { cystic ovary }(n=1)\end{array}$ & 13 \\
\hline & Benign (uterine corpus): leiomyoma $(n=6)$, other lesions $(n=3)$ & 9 \\
\hline Unknown $(\mathrm{n}=7)$ & Unknown & 7 \\
\hline
\end{tabular}

Table II. Groups, classification and definitions used in the present study for cytological evaluation $(\mathrm{n}=173)$.

A, Negative group

Cytological classification

Definition

Cases, $\mathrm{n}$

Normal

Absence of atypical or abnormal cells

Reactive

Atypical cells present but without abnormal features

$\mathrm{B}$, Positive group

Cytological classification

Definition

Cases, $\mathrm{n}$

Suspicious

Suspicious for malignancy

Malignant
Cells with abnormal features suggestive but not conclusive for malignancy

Cells and cell clusters fairly conclusive for malignancy

Cells and cell clusters conclusive for malignancy
However, for 26 specimens, different protocols were used for SDN detection based on the condition of the specimens, for example the color of the cells, the background color or debris. All image analysis protocols are summarized in Table SI. A total of 47 specimens were excluded due to impediments arising from excessive background mucus, red blood cells, hemosiderin-incorporated macrophages, pale cells, cell aggregates or overlapping cells. The CiCP emergence rate (CER) per SDN was defined as follows: CER/SDN $(\%)=$ total $\mathrm{CiCP}$ number/total SDN x00. 


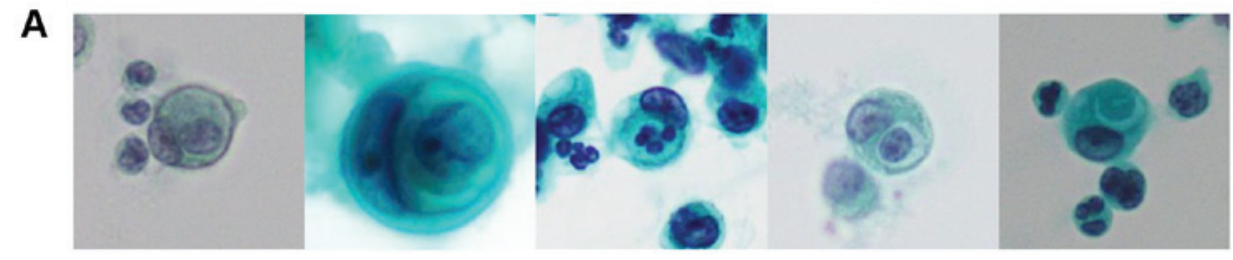

a: $M \phi$ in $M \phi \quad$ b: Cancer in cancer c: Neutrophil in $M \phi d$ : Lymphocyte in $\mathbf{M} \phi \quad$ e: $\mathbf{R B C}$ in $\mathbf{M} \phi$

\begin{tabular}{ll}
\hline & Nuclear area \\
\hline \hline $\begin{array}{l}\text { Outer cells } \\
\text { Macrophages } \\
(n=1629)\end{array}$ & 39.119415 .1011 \\
$\begin{array}{l}\text { Cancer cells } \\
(n=91)\end{array}$ & 70.473938 .3871 \\
$\begin{array}{c}\text { Mesothelial cells } \\
(n=46)\end{array}$ & $\mathbf{5 4 . 2 6 6 0 3 1 . 6 6 1 7}$ \\
\hline
\end{tabular}

\begin{tabular}{lll}
\hline & \multicolumn{2}{l}{ Nuclear area } \\
\hline \hline \begin{tabular}{l} 
Average SD \\
\hline $\begin{array}{l}\text { Lymphoc cells } \\
(n=1244)\end{array}$
\end{tabular} & 17.8797 & 5.7799 \\
\hline $\begin{array}{l}\text { Neutrophils } \\
(n=192)\end{array}$ & 16.7180 & 6.3608 \\
\hline $\begin{array}{l}\text { Red blood cells } \\
(n=184)\end{array}$ & 17.9100 & 6.9658 \\
\hline $\begin{array}{l}\text { Macrophages } \\
(n=134)\end{array}$ & 34.4524 & 17.2613 \\
\hline $\begin{array}{l}\text { Cancer cells } \\
(n=82)\end{array}$ & 69.0059 & 33.3489 \\
\hline $\begin{array}{l}\text { Mesothelial cells } \\
(n=18)\end{array}$ & 53.2231 & 28.5908 \\
\hline $\begin{array}{l}\text { Eosinophils } \\
(n=14)\end{array}$ & 10.3614 & 1.9792 \\
\hline
\end{tabular}

Figure 2. Representative $\mathrm{CiCP}$ and nuclear area analyses for each cellular component. (A) Representative CiCP cases (Pap staining; magnification, $\mathrm{x} 40$ ). Nuclear area analyses for (B) outer cells and (C) inner cells of $105 \mathrm{CiCP}$ cases. CiCP, cell-in-cell phenomena; $\mathrm{M} \phi$, macrophages; RBC, red blood cell.

Evaluation of white blood cell count. Data on white blood cell counts of the peripheral blood samples collected at the closest date before ascites or peritoneal washing sample collection were extracted from the electronic health record system of Gunma University Hospital.

Statistical analysis. Statistical analyses were performed using JMP Pro v12.2.0 software (SAS Institute, Inc.). The associations between two categorical variables were calculated using the $\chi^{2}$ test, and the differences between the mean of two groups were calculated using Welch's unpaired t-test. For non-parametric comparisons between two groups, Wilcoxon rank-sum test was used. For multiple pair-wise comparison, Steel-Dwass test was used. In order to determine the cut-off value, receiver operating characteristic (ROC) analysis was performed, and the value that gave the highest sensitivity and 1-specificity was regarded as the cut-off value. The data were presented as box plots (median and interquartile range) or as the mean and SD. $\mathrm{P}<0.05$ was considered to indicate a statistically significant difference.

\section{Results}

Results of manual evaluation and identification of incorporated cells and host cells in CiCP are associated with those of the image analysis for NA evaluation. Among the 173 cases examined in the present study, $\mathrm{CiCP}$ were detected in 105 cases. In these cases, as shown in Fig. 2B and C, the host cells included macrophages, mesothelial cells and cancer cells, while the incorporated cells included lymphocytes, neutrophils, eosinophils, mesothelial cells, macrophages, erythrocytes and cancer cells. A total of 13 cases exhibited cell cannibalism: Adenocarcinoma of the stomach (3 cases); serous carcinoma of the uterine corpus (2 cases); serous carcinoma of the ovary ( 2 cases); endometrioid carcinoma of the ovary (1 case); carcinosarcoma of the ovary (1 case); granulosa cell tumor (1 case); malignant ovarian tumor (histology unknown; 1 case); high-grade urothelial carcinoma (1 case); and carcinoma of unknown origin (1 case) (Table SII). Comparison of the NAs of the host and incorporated cells among the groups revealed significant differences, except for the pairwise comparison of incorporated cells between erythrocytes and neutrophils, mesothelial cells and cancer cells, and erythrocytes and lymphocytes (Table SIII). The present results suggested mutual agreement between the results of manual evaluation and image analysis.

Rate of CiCP-positive cases (RCPCs) and CiCP emergence rate (CER) per SDN are significantly lower in peritoneal washing than in ascites samples. The RCPCs and CER per SDN were analyzed for both peritoneal washing and ascites samples. The RCPCs and CER/SDN ratio were significantly lower in the peritoneal washing samples than in ascites samples. The percentage of the RCPCs was $45.3 \%$ in the peritoneal washing samples and $79.5 \%$ in the ascites samples $(\mathrm{P}<0.0001$; Fig. 3A). On the other hand, the CER/SDN was $0.006 \%$ in the peritoneal washing samples and $0.020 \%$ in the ascites samples, as shown in Fig. 3B ( $\mathrm{P}=0.0026$; Fig. 3B). The average SDN number was 103,906 cells $/ \mathrm{cm}^{2}$ in the peritoneal washing samples and 119,508 cells $/ \mathrm{cm}^{2}$ in the ascites samples, 
but the difference was not statistically significant $(\mathrm{P}=0.8063$; Fig. 3C). The present results indicated that in ascites, both the RCPCs and CER/SDN ratio were increased compared with in peritoneal washing samples, and $\mathrm{CiCP}$ was present in visually undetectable ascites (59\% of CiCP-positive cases were derived from ascites and $41 \%$ from peritoneal washing samples) in the cytological specimens.

RCPCs and CER per SDN are significantly higher in the cytologically positive group than in the negative group. The RCPCs and CER/SDN ratio were analyzed for the cytologically positive and negative groups. Fig. 4A indicated that there was a significant association between CiCP status and cytological status $(\mathrm{P}=0.0220)$. On the other hand, the CER/SDN was $0.009 \%$ in the negative group and $0.024 \%$ in the positive group, as shown in Fig. 4B ( $\mathrm{P}=0.0312$; Fig. 4B). The average number of SDN, as shown in Fig. 4C, was 107,242 cells $/ \mathrm{cm}^{2}$ in the negative group and 144,508 cells $/ \mathrm{cm}^{2}$ in the positive group, but the difference was not statistically significant $(\mathrm{P}=0.2471$; Fig. 4C). The present results indicated that both the RCPCs and CER/SDN ratio were increased in malignant cytological samples.

Rate of NI in the total CiCP cells is significantly higher in the cytologically positive group than in the negative group. The components of $\mathrm{CiCP}$ for host cells and incorporated cells were evaluated in each case based on the classification of cytologically positive and negative groups, and summarized in Table III. Briefly, the rate of incorporated lymphocytes among the total incorporated cells was significantly lower in the positive group than in the negative group $(\mathrm{P}<0.0001$; Table III), while the rate of incorporated neutrophils among the total incorporated cells was significantly higher in the positive group than in the negative group ( $\mathrm{P}=0.0288$; Table III). By contrast, the rate of incorporating host macrophages in the total host cells was significantly lower in the positive group than in the negative group $(\mathrm{P}=0.0083$; Table III). Except for cancer cells, rates of the other incorporated cells among the total incorporated cells and the other incorporating host cells (such as mesothelial cells) among the total incorporating cells were not significantly different (Table III). Neutrophils were mostly incorporated by macrophages (data not shown). However, NI by cells that were not macrophages was seldom observed (three mesothelial cells and one cancer cell as host cells). Therefore, the present data suggested that NI by macrophages, or neutrophil emperipolesis, may be increased in malignant samples.

High NI rate in CiCP cells implicates cytological malignancy and high peripheral blood leukocyte (PBL) count. As the NI rate per total CiCP cells was increased in malignant samples as shown in Table III, a cut-off value of NI rate was determined per total $\mathrm{CiCP}$ cells to distinguish cytologically positive samples from negative samples. Firstly, the ROC curve between the NI rate per total $\mathrm{CiCP}(\mathrm{NI} / \mathrm{CiCP})$ and cytological classification (negative or positive) was evaluated. As shown in Fig. 5A and Table SIV, the cut-off value for NI/CiCP to distinguish the positive group from the negative group was $11.1 \%$, and the area under the ROC curve was 0.62409. Samples were classified according to this cut-off value and the percentages of a

\begin{tabular}{|c|c|c|c|c|}
\hline & CiCP(-) Cases & CiCP(+) Cases & Total & Significance \\
\hline $\begin{array}{l}\text { Peritoneal } \\
\text { washing }\end{array}$ & $\begin{array}{c}52(54.7 \%) \\
(76.5 \%)\end{array}$ & $\begin{array}{c}43 \\
(41.0 \%)\end{array}$ & $95 \quad(100 \%)$ & \multirow{2}{*}{${ }^{a} P<0.0001$} \\
\hline Ascites & $\begin{array}{c}16(20.5 \%) \\
(23.5 \%)\end{array}$ & $\begin{array}{l}62(79.5 \%) \\
(59.0 \%)\end{array}$ & $78 \quad(100 \%)$ & \\
\hline Total & $\begin{array}{c}68 \\
(100 \%)\end{array}$ & $\begin{array}{c}105 \\
(100 \%)\end{array}$ & 173 & \\
\hline
\end{tabular}
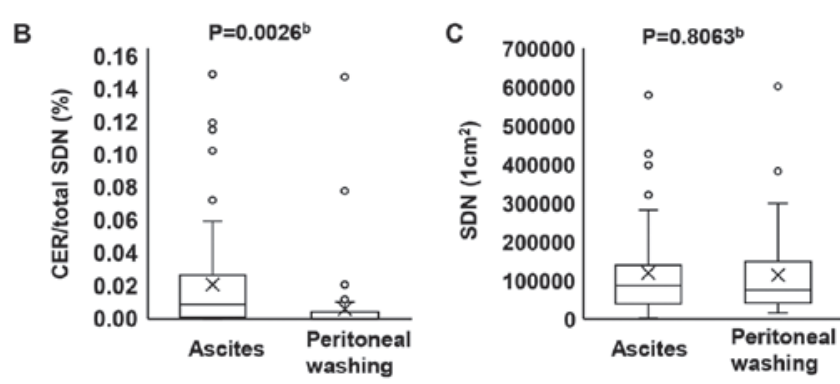

Figure 3. Analysis of CiCP by sample type. (A) Contingency table of presence/absence of $\mathrm{CiCP}$ by sample type. (B) CER/total SDN by sample type. (C) Comparison of number of SDN by sample type. The ' $\mathrm{X}$ ' mark indicates the mean and the box with a horizontal line indicates the median and interquartile range. Error bars indicate maximum and minimum values. Circles indicate outliers. ${ }^{a} \chi^{2}$ test. ${ }^{b}$ Welch's test. CiCP, cell-in-cell phenomena; SDN, singly detectable nuclei; CER, CiCP emergence rate.

\begin{tabular}{|c|c|c|c|c|}
\hline & CiCP(-) Cases & CiCP(+) Cases & Total & Significance \\
\hline Negative & $\begin{array}{c}59 \\
(86.8 \%)\end{array}$ & $\begin{array}{c}76 \quad(56.3 \%) \\
(72.4 \%)\end{array}$ & $135(100 \%)$ & \multirow{2}{*}{$\mathrm{P}=0.0220^{2}$} \\
\hline Positive & $\begin{array}{c}9 \\
(13.2 \%)\end{array}$ & $\underset{(27.6 \%)}{29}(76.3 \%)$ & $38 \quad(100 \%)$ & \\
\hline Total & $\begin{array}{c}68 \\
(100 \%)\end{array}$ & $\begin{array}{c}105 \\
(100 \%)\end{array}$ & 173 & \\
\hline
\end{tabular}

B
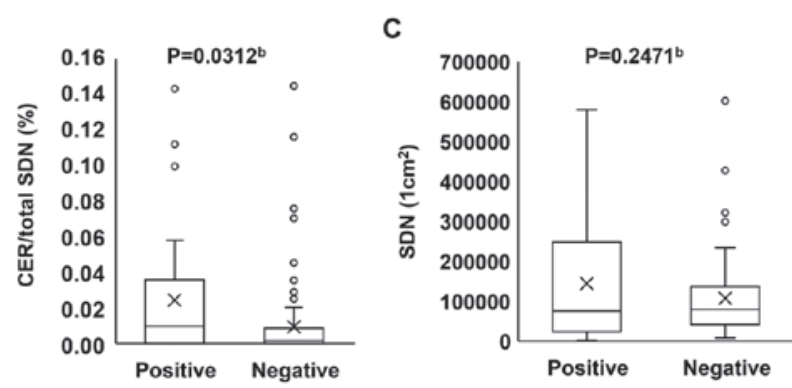

Figure 4. Analysis of CiCP by cytological group (positive/negative) (A) Contingency table of presence/absence of $\mathrm{CiCP}$ by cytological group. (B) CER/total SDN by cytological group. (C) Comparison for number of SDN by cytological group. The ' $\mathrm{X}$ ' mark indicates the mean and the box with a horizontal line indicates the median and interquartile range. Error bars indicate maximum and minimum values. Circles indicate outliers. ${ }^{a} \chi^{2}$ test.

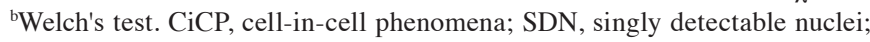
CER, CiCP emergence rate.

positive cytology rate were compared. As shown in Fig. 5B, the positive cytology rate was $46.4 \%$ in high NI/CiCP specimens and $20.8 \%$ in low $\mathrm{NI} / \mathrm{CiCP}$ specimens $(\mathrm{P}=0.0115)$. The CER per total SDN was $0.017 \%$ in the high $\mathrm{NI} / \mathrm{CiCP}$ and $0.021 \%$ in the low NI/CiCP specimens, but the difference was not statistically significant ( $\mathrm{P}=0.4900$; Fig. 5C). Fig. 5D presents the numbers of PBLs at the nearest date before the cytological sample was collected. The PBL count was $9.30 \times 10^{3}$ cells $/ \mu 1$ in the high $\mathrm{NI} / \mathrm{CiCP}$ specimens and $5.84 \times 10^{3}$ cells $/ \mu 1$ in the low NI/CiCP specimens, but the difference was not statistically significant $(\mathrm{P}=0.0724)$, whereas a statistically significant difference was observed using the Wilcoxon rank-sum test 
Table III. Components of cell-in-cell phenomena in cytologically negative $(n=76)$ and positive ( $n=29)$ groups.

A, Host cells (outer cells)

\begin{tabular}{lccr}
\hline & \multicolumn{2}{c}{ Mean component ratio, \% (SD) } & \\
\cline { 2 - 3 } Cells & Cytologically negative group & Cytologically positive groups & P-value $^{\mathrm{a}}$ \\
\hline Macrophages & $95.39(16.88)$ & $76.00(40.15)$ & 0.0083 \\
Cancer cells & 0 & $23.72(39.79)$ & $<0.0001$ \\
Mesothelial cells & $4.61(16.88)$ & $0.29(1.27)$ & 0.1964 \\
\hline
\end{tabular}

$\mathrm{B}$, Incorporated cells (inner cells)

\begin{tabular}{|c|c|c|c|}
\hline \multirow[b]{2}{*}{ Cells } & \multicolumn{2}{|c|}{ Mean component ratio, $\%$ (SD) } & \multirow[b]{2}{*}{ P-value } \\
\hline & Cytologically negative group & Cytologically positive group & \\
\hline Lymphocytes & $68.64(34.56)$ & $35.82(35.62)$ & $<0.0001$ \\
\hline Neutrophils & $10.15(22.80)$ & $17.56(26.09)$ & 0.0288 \\
\hline Macrophages & $8.92(17.83)$ & $17.09(29.06)$ & 0.1938 \\
\hline Cancer cells & 0 & $18.44(35.49)$ & $<0.0001$ \\
\hline Red blood cells & $8.11(19.55)$ & $10.85(23.85)$ & 0.2881 \\
\hline Mesothelial cells & $3.87(16.47)$ & $0.26(1.12)$ & 0.2569 \\
\hline Eosinophils & $0.31(2.68)$ & 0 & 0.5368 \\
\hline
\end{tabular}

${ }^{a}$ Wilcoxon's rank-sum test.

$(\mathrm{P}=0.0022)$. The present findings suggested that a change in the immune condition of a patient may result in a high NI.

\section{Discussion}

In the present study, the term $\mathrm{CiCP}$ was used for emperipolesis and cell cannibalism since both phenomena have similar mechanisms in terms of the formation of a distinct halo structure around the incorporated cells in the host cells (4). Emperipolesis involves hematopoietic cells, whereas cell cannibalism involves tumor cells (11). Therefore, if the host tumor cells incorporate hematopoietic cells, the phenomenon can be termed either emperipolesis or cell cannibalism. In the present study, cell cannibalism was observed in 13 cases (Table SII). Among them, the host tumor cells incorporated hematopoietic cells in six specimens (data not shown). In addition, few $\mathrm{CiCP}$ were detected that involved mesothelial cells, either as ingested or host cells, although neither emperipolesis nor cell cannibalism generally involves mesothelial cells. Therefore, in the present study, CiCP is the correct term to explain the internalization of viable cells by host cells.

It is important to recognize the usefulness of image analysis. The present study focused on NA image analysis to evaluate manual classification of $\mathrm{CiCP}$ by consensus agreement among the evaluators since reproducibility of pathological diagnosis is often reported in the literature $(25,26)$. Image analysis revealed that host cells were composed of three cell types: Macrophages, mesothelial cells and tumor cells. The NA of these three cell types was markedly different from each other. Notably, the NAs of the incorporated cells were also markedly different among most of the cell types. In pathological practice, a number of cellular features, including NA, nuclear shape, nuclear density and nuclear/cytoplasmic ratio, are used to distinguish one cell type from another (14). This kind of comprehensive evaluation enables differentiation of cells via manual observation. However, the present image analysis data suggested that NA has an important central role in distinguishing cell types. Manual observation and software-based image analysis can detect most cells at the level of $10^{3}$ cells (27). However, in the present study, a virtual slide-format-based image was used to count cells, which allowed to count $>10^{5}$ cells in one sample and to calculate the emergence rate of a low emergence rate phenomenon, such as $\mathrm{CiCP}$. Therefore, virtual slide-format-based image analysis may provide an improved method for specimen evaluation.

Finally, the significance of $\mathrm{CiCP}$ in patients with cancer should be discussed. Three notable results were found in patients with cancer: CER was increased in malignant cytological specimens of the peritoneal cavity fluid, NI was increased in malignant cytological specimens and high NI specimens exhibited a high PBL count. The present results indicated that $\mathrm{CiCP}$ may alter the immune response of a patient. Macrophages were the main host cell type in $\mathrm{CiCP}$, and increased CiCP was observed in the tumor specimens. Historically, macrophages have been classified into several subtypes according to their activation status (28), frequently as 'Th1 cytokine-based activation phenotype' M1 and 'Th2 cytokine-based activation phenotype' M2 (29). In general, 
A

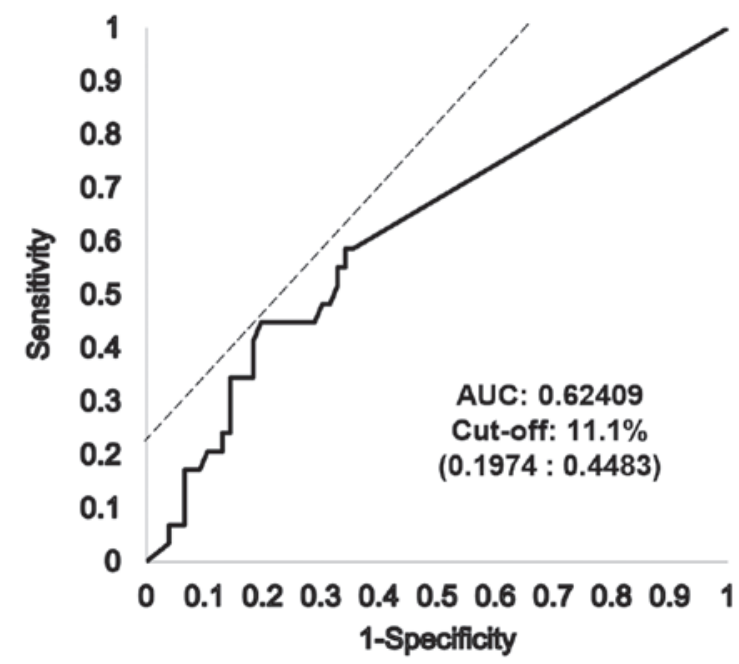

B

\begin{tabular}{|c|c|c|c|c|}
\hline & Negative & Positive & Total & Significance \\
\hline High NI cases & $\begin{array}{c}15(53.6 \%) \\
(19.7 \%)\end{array}$ & $\begin{array}{c}13 \\
(44.8 \%)\end{array}$ & $28 \quad(100 \%)$ & \\
\hline Low NI cases & $\begin{array}{c}61 \\
(79.2 \%) \\
(80.3 \%)\end{array}$ & $\begin{array}{c}16 \\
(55.2 \%)\end{array}$ & 77 (100\%) & $P=0.0115^{a}$ \\
\hline Total & $\begin{array}{c}76 \\
(100 \%)\end{array}$ & $\begin{array}{c}29 \\
(100 \%)\end{array}$ & 105 & \\
\hline
\end{tabular}

C

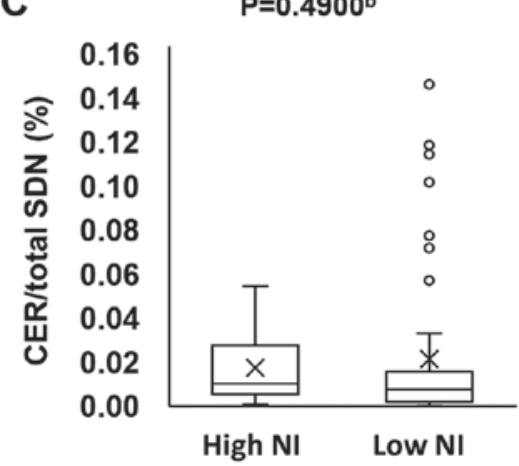

D

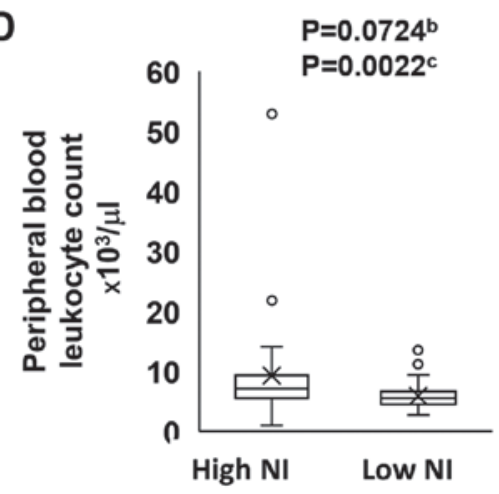

Figure 5. Analysis of NI and peripheral blood leukocytes count.(A) Receiver operating characteristic curve for NI and cytological groups (1-Specificity:Sensitivity). (B) Contingency table for cytological classification and high and low NI groups. (C) Comparison of CER/total SDN between the high and low NI groups. (D) Comparison of peripheral blood leukocytes count between the high and low NI groups. The ' $\mathrm{X}$ ' mark indicates the mean and the box with a horizontal line indicates the median and interquartile range. Error bars indicate maximum and minimum values. Circles indicate outliers. ${ }^{a} \chi^{2}$ test. ${ }^{b} \mathrm{Welch}$ 's test. ${ }^{\mathrm{c}} \mathrm{Wilcoxon}$ 's rank-sum test. CiCP, cell-in-cell phenomena; SDN, singly detectable nuclei; CER, CiCP emergence rate; NI, neutrophil incorporation; AUC, area under the curve.

M1 macrophages are considered as antitumor and immune promoting, while M2 macrophages are considered as pro-tumor (30). Tumor-associated macrophages (TAMs) are predominantly the M2 phenotype and help promote tumor angiogenesis, tumor survival and tumor metastasis (31). Additionally, the infiltration of high numbers of TAMs into a tumor site has been associated with a poor prognosis in numerous types of tumor (32), including breast (33), prostate (34), endometrial (35) and urinary bladder (36) cancer, malignant melanoma (37) and malignant lymphoma (38). Additionally, peritoneal macrophages can acquire an M2-tumor-promoting function (39). The present findings suggested that peritoneal macrophages may have an M2 phenotype and may incorporate more immune cells and help tumor cells avoid immune surveillance. The present study could not definitely determine whether $\mathrm{CiCP}$ was one of the characteristics of M2-type macrophages. To the best of our knowledge, no previous pathology- or cytology-associated study has reported cytological findings of $\mathrm{CiCP}$, which may be due to the very low emergence rate of $\mathrm{CiCP}$ in specimens. In addition, since most host cells of $\mathrm{CiCP}$ were macrophages in the present study (Table III), from a cytological viewpoint, an important finding of the current study was that $\mathrm{CiCP}$ in macrophages may be a novel characteristic of TAMs in ascites of patients with cancer. Recent studies on tumor immunity have revealed that tumor-bearing conditions can alter myeloid differentiation and lead to the induction of TAMs, as well as dendritic cells, myeloid-derived suppressor cells and neutrophils, to sustain the immunosuppressive environment of tumor tissues (40-42). Tumor-associated neutrophils (TANs) promote tumor 
angiogenesis (43) and epithelial to mesenchymal transition (44) in gastric cancer. In addition, previous clinical studies revealed that a high neutrophil-to-lymphocyte ratio of PBLs predicted an unfavorable disease-specific survival $(45,46)$. In addition, Araki et al (47) reported that a low absolute lymphocyte count in PBLs revealed a poor prognosis in patients with advanced breast cancer. The aforementioned reports suggest that the pro-tumor function of TANs, as well as an increased neutrophil ratio in PBLs, can lead to a poor prognosis. In the current study, the increased number of PBLs was one of the reasons for increased NI in tumor ascites. Notably, there are no reports on CiCP involving NI by macrophages, although NI by tumor cells has been demonstrated in numerous types of tumor, including anaplastic carcinoma of the gall bladder, adenocarcinoma of the small intestine and pancreas, infiltrating duct carcinoma of the breast, squamous cell carcinoma of the larynx, small cell carcinoma of the lung and malignant lymphoma (8).

In conclusion, the present findings shed light on tumor-immunity-associated phenomena, especially since increased emperipolesis by macrophages in a tumor microenvironment may allow to detect novel characteristics of TAMs in the peritoneal cavity fluid. Therefore, during cytological specimen screening for atypical cells, it is very important to observe other background findings such as emperipolesis and cannibalism, in addition to atypical cells. In the present study, macrophage characteristics, such as M1/M2 polarization, were not further investigated. Therefore, future studies should investigate macrophage characteristics using freshly collected ascites.

\section{Acknowledgements}

Not applicable.

\section{Funding}

The present study was supported by Gunma University.

\section{Availability of data and materials}

The datasets used and/or analyzed during the current study are available from the corresponding author on reasonable request.

\section{Authors' contributions}

MF conducted clinical data collection and specimen screening. MS developed the experimental design. MF and MS participated in discussions in meetings to reach a consensus, performed nuclear tracing and nuclear area analysis, digital imaging of the specimens by virtual slide scanner, image analysis for SDN, statistical analysis and figure and manuscript preparation. HT and SF performed specimen screening. SK participated in discussions in meetings to reach a consensus, digital imaging of the specimens by virtual slide scanner, determination of condition for SDN in image analysis and figure preparation. YN assisted in clinical data collection, determination of condition for SDN in image analysis and manuscript preparation. JH, TO and TF assisted in cytological review of the cases and manuscript reviewing. All authors read and approved the final manuscript.

\section{Ethics approval and consent to participate}

The present research was approved by the Gunma University Ethical Review Board (GUERB) for Medical Research Involving Human Subjects of Gunma University School of Medicine (Maebashi, Japan), and the possibility of publishing the study results was stated on the public webpage of the hospital as part of an information disclosure document. Additionally, the possibility to decline participation in the study was provided according to the Ethical Guidelines for Medical and Health Research Involving Human Subjects of the Japanese government (Ministry of Education, Culture, Sports, Science and Technology, and the Ministry of Health, Labor and Welfare). Informed consent was waived by the GUERB based on the aforementioned guidelines due to the retrospective nature of the study.

\section{Patient consent for publication}

Not applicable.

\section{Competing interests}

The authors declare that they have no competing interests.

\section{References}

1. Lewis W: The engulfment of living blood cells by others of the same type. Anatomical Record 31: 43-49, 1925.

2. Humble JG, Jayne WH and Pulvertaft RJ: Biological interaction between lymphocytes and other cells. Br J Haematol 2: 283-294, 1956.

3. Gupta N, Jadhav K and Shah V: Emperipolesis, entosis and cell cannibalism: Demystifying the cloud. J Oral Maxillofac Pathol 21: 92-98, 2017.

4. Rastogi V, Sharma R, Misra SR, Yadav L and Sharma V: Emperipolesis-a review. J Clin Diagn Res 8: ZM01-ZM02, 2014.

5. Samii K and Pasteur E: Images in hematology. Emperipolesis. Am J Hematol 59: 64, 1998

6. Rosai J and Dorfman RF: Sinus histiocytosis with massive lymphadenopathy. A newly recognized benign clinicopathological entity. Arch Pathol 87: 63-70, 1969.

7. Foucar E, Rosai J and Dorfman R: Sinus histiocytosis with massive lymphadenopathy (Rosai-Dorfman disease): Review of the entity. Semin Diagn Pathol 7: 19-73, 1990.

8. Singhal N, Handa U, Bansal C and Mohan H: Neutrophil phagocytosis by tumor cells-a cytological study. Diagn Cytopathol 39: 553-555, 2011.

9. Kale A: Cellular Cannibalism. J Oral Maxillofac Pathol 19: 7-9, 2015.

10. Bansal C, Tiwari V, Singh U, Srivastava A and Misra J: Cell cannibalism: A cytological study in effusion samples. J Cytol 28: 57-60, 2011.

11. Sharma N and Dey P: Cell cannibalism and cancer. Diagn Cytopathol 39: 229-233, 2011.

12. Fais S: Cannibalism: A way to feed on metastatic tumors. Cancer Lett 258: 155-164, 2007.

13. Richards DM and Endres RG: How cells engulf: A review of theoretical approaches to phagocytosis. Rep Prog Phys 80: $126601,2017$.

14. Koss L and Melamed M: Fundamental concepts of neoplasia: Benign tumor and cancer. In: Koss's diagnostic cytology and its histopathologic bases. Koss L and Melamed M (eds.) Lippincott Williams \& Wilkins, Philadelphia, pp143-179, 2006.

15. Al-Abbadi M: Warthin's tumor. In: Salivary gland Cytology. Al-Abbadi M (ed.) Wiley-Blackwell, Hobokwnm NJ, pp69-75, 2011.

16. Kini S (ed): Gonads (Ovaries ans Testis). In: Color atlas of diagnosis in exfoliative and aspiration cytopathology. Wolters Kluwer/Lipponcott Williams \& Wilkins, Philadelphia, PA, pp852-869, 2011. 
17. Saxena S, Beena KR, Bansal A and Bhatnagar A: Emperipolesis in a common breast malignancy. A case report. Acta Cytol 46: 883-886, 2002.

18. Rane SR, Parkhi M, Vishwasrao S and Nakate L: Non-Hodgkin's lymphoma with extensive emperipolesis mimicking Rosai-Dorfman disease: A rare case report. Indian J Pathol Microbiol 62: 319-322, 2019.

19. Meykler S, Baloch ZW and Barroeta JE: A case of marginal zone lymphoma with extensive emperipolesis diagnosed on pleural effusion cytology with immunocytochemistry and flow cytometry. Cytopathology 27: 70-72, 2016.

20. Lopes LF, Bacchi MM, Coelho KI, Filho AA and Bacchi CE: Emperipolesis in a case of B-cell lymphoma: A rare phenomenon outside of Rosai-dorfman disease. Ann Diagn Pathol 7: 310-313, 2003.

21. Pinto D and Schmitt F: Current applications of molecular testing on body cavity fluids. Diagn Cytopathol: Mar 30, 2020 (Epub ahead of print).

22. Renshaw AA: Quality improvement in cytology: Where do we go from here? Arch Pathol Lab Med 135: 1387-1390, 2011.

23. Ministry of Education Culture, Sports, Science and Technology, and Ministry of Health, Labor and Welfare: Ethical guidelines for medical and health research involving human subjects. https://www. mhlw.go.jp/file/06-Seisakujouhou-10600000-Daijinkanboukouseikagakuka/0000080278.pdf. Accessed March 31, 2015.

24. Smith P and Gray W: Cervical intraepithelial neoplasia and squamous cell carcinoma of the cervix. In: Diagnostic Cytopathology. Gray W and Kocjan G (eds). Churchill Livingstone Elsevier, London, pp609-644, 2010.

25. Nakazato Y, Maeshima AM, Ishikawa Y, Yatabe Y, Fukuoka J, Yokose T, Tomita Y, Minami Y, Asamura H, Tachibana K, et al: Interobserver agreement in the nuclear grading of primary pulmonary adenocarcinoma. J Thorac Oncol 8: 736-743, 2013.

26. Grilley-Olson JE, Hayes DN, Moore DT, Leslie KO, Wilkerson MD, Qaqish BF, Hayward MC, Cabanski CR, Yin X, Socinski MA, et al: Validation of interobserver agreement in lung cancer assessment: Hematoxylin-eosin diagnostic reproducibility for non-small cell lung cancer: The 2004 World Health Organization classification and therapeutically relevant subsets. Arch Pathol Lab Med 137: 32-40, 2013.

27. Lindauer K, Bartels T, Scherer P and Kabiri M: Development and validation of an image analysis system for the measurement of cell proliferation in mammary glands of rats. Toxicol Pathol 47 634-644, 2019

28. Gordon S: Alternative activation of macrophages. Nat Rev Immunol 3: 23-35, 2003.

29. Mantovani A, Sozzani S, Locati M, Allavena P and Sica A: Macrophage polarization: Tumor-associated macrophages as a paradigm for polarized M2 mononuclear phagocytes. Trends Immunol 23: 549-555, 2002.

30. Yunna C, Mengru H, Lei W and Weidong C: Macrophage M1/M2 polarization. Eur J Pharmacol 877: 173090, 2020.

31. Sica A, Larghi P, Mancino A, Rubino L, Porta C, Totaro MG, Rimoldi M, Biswas SK, Allavena P and Mantovani A: Macrophage polarization in tumour progression. Semin Cancer Biol 18: 349-355, 2008.

32. Lewis CE and Pollard JW: Distinct role of macrophages in different tumor microenvironments. Cancer Res 66: 605-612, 2006.

33. Leek RD, Landers RJ, Harris AL and Lewis CE: Necrosis correlates with high vascular density and focal macrophage infiltration in invasive carcinoma of the breast. Br J Cancer 79: 991-995, 1999.
34. Lissbrant IF, Stattin P, Wikstrom P, Damber JE, Egevad L and Bergh A: Tumor associated macrophages in human prostate cancer: Relation to clinicopathological variables and survival. Int J Oncol 17: 445-451, 2000.

35. Ohno S, Ohno Y, Suzuki N, Kamei T, Koike K, Inagawa H, Kohchi C, Soma G and Inoue M: Correlation of histological localization of tumor-associated macrophages with clinicopathological features in endometrial cancer. Anticancer Res 24: 3335-3342, 2004

36. Hanada T, Nakagawa M, Emoto A, Nomura T, Nasu N and Nomura Y: Prognostic value of tumor-associated macrophage count in human bladder cancer. Int J Urol 7: 263-269, 2000.

37. Mäkitie T, Summanen P, Tarkkanen A and Kivelä T: Tumor-infiltrating macrophages (CD68(+) cells) and prognosis in malignant uveal melanoma. Invest Ophthalmol Vis Sci 42: 1414-1421, 2001.

38. Farinha P, Masoudi H, Skinnider BF, Shumansky K, Spinelli JJ, Gill K, Klasa R, Voss N, Connors JM and Gascoyne RD: Analysis of multiple biomarkers shows that lymphoma-associated macrophage (LAM) content is an independent predictor of survival in follicular lymphoma (FL). Blood 106: 2169-2174, 2005.

39. Ko SY, Ladanyi A, Lengyel E and Naora H: Expression of the homeobox gene HOXA9 in ovarian cancer induces peritoneal macrophages to acquire an M2 tumor-promoting phenotype. Am J Pathol 184: 271-281, 2014

40. Law AMK, Valdes-Mora F and Gallego-Ortega D: Myeloid-derived suppressor cells as a therapeutic target for cancer. Cells 9: 561, 2020.

41. Mukaida N, Sasaki SI and Baba T: Two-faced roles of tumorassociated neutrophils in cancer development and progression. Int J Mol Sci 21: 3457, 2020.

42. Schupp J, Krebs FK, Zimmer N, Trzeciak E, Schuppan D and Tuettenberg A: Targeting myeloid cells in the tumor sustaining microenvironment. Cell Immunol 343: 103713, 2019.

43. Li TJ, Jiang YM, Hu YF, Huang L, Yu J, Zhao LY, Deng HJ, Mou TY, Liu H, Yang Y, et al: Interleukin-17-producing neutrophils link inflammatory stimuli to disease progression by promoting angiogenesis in gastric cancer. Clin Cancer Res 23: 1575-1585, 2017.

44. Li S, Cong X, Gao H, Lan X, Li Z, Wang W, Song S, Wang Y, Li C, Zhang H, et al: Tumor-associated neutrophils induce EMT by IL-17a to promote migration and invasion in gastric cancer cells. J Exp Clin Cancer Res 38: 6, 2019.

45. Wang SC, Chou JF, Strong VE, Brennan MF, Capanu M and Coit DG: Pretreatment neutrophil to lymphocyte ratio independently predicts disease-specific survival in resectable gastroesophageal junction and gastric adenocarcinoma. Ann Surg 263: 292-297, 2016.

46. Ock CY, Nam AR, Lee J, Bang JH, Lee KH, Han SW, Kim TY, Im SA, Kim TY, Bang YJ, et al: Prognostic implication of antitumor immunity measured by the neutrophil-lymphocyte ratio and serum cytokines and angiogenic factors in gastric cancer. Gastric Cancer 20: 254-262, 2017.

47. Araki K, Ito Y, Fukada I, Kobayashi K, Miyagawa Y, Imamura M, Kira A, Takatsuka Y, Egawa C, Suwa H, et al: Predictive impact of absolute lymphocyte counts for progression-free survival in human epidermal growth factor receptor 2-positive advanced breast cancer treated with pertuzumab and trastuzumab plus eribulin or nab-paclitaxel. BMC Cancer 18: 982, 2018. 